\title{
Coastal Community's Knowledge, Attitude and Perception on Beach Forest Ecosystem Services in Socorro, BucasGrande Islands, Surigao del Norte, Philippines: Factors Affecting their Utilization and Management
}

\author{
Collao, E.H.C. ${ }^{1}$, Tatil, W.T. ${ }^{2 *}$ \\ ${ }^{1}$ BS Biology (Botany), Department of Biological Sciences, College of Science \& Mathematics, \\ Mindanao State University, Iligan Institute of Technology, Philippines \\ ${ }^{2}$ Department of Biological Sciences, College of Science \& Mathematics, Mindanao State \\ University, Iligan Institute of Technology, Iligan City, Philippines \\ *wella.tatil@g.msuiit.edu.ph
}

\begin{abstract}
In the Philippines, beach forest ecosystems have been beneficial to coastal communities not only in their economic aspects, but also for their ecological values. Hence, there is a need for sustainable management of coastal ecosystems to ensure the survival of the local inhabitants as well as the terrestrial and marine biodiversity as a whole. In order to achieve sustainability, efforts should not be confined to natural resource conservation alone, but an effective integration of community's knowledge, attitude and perception on the resource value can be an important element to optimize positive impacts. Integration of local's knowledge, attitudes and perceptions on resources management and conservation has been practiced for other natural ecosystems, but less used for beach forest ecosystems. This is despite the fact that beach forest ecosystem plays a vital role in protecting the coastal communities from hazard vulnerability, among many other services. Hence, this study evaluates the knowledge, attitudes and perceptions of two coastal barangays in Socorro, Bucas Grande Island towards beach forest ecosystem services, and their conservation and management importance. A total of 188 respondents were surveyed using semistructured questionnaire. Key informant (KI) interviews were also employed to elicit information about the conservation and management efforts by the local government and People's Organisations (POs).Using descriptive statistics, result showed that local people in both communities have sufficient knowledge on the beach forest services and have positive attitudes in utilizing the resources and conserving the ecosystem because of positive intervention such as environmental seminars and tree-planting programs initiated by Local Government Units (LGUs).Moreover, both sites were managed by POs called Pamosaingan Farmers and Fishermen Association (PAFAFIA) and Sta. Cruz Farmers and Fishermen Association (SACFFA). These organizations implemented different strategies in managing and protecting the beach and mangrove forest such as recording of reports on illegal cutting of trees and mangroves and sand hoarding. However, 3\% of the respondents did not participate in the activities of said organizations due of issues on transparency and dissatisfaction with the management strategies implemented. Despite these, with the majority (97\%) of the respondents who are willing to participate in the management and conservation of beach forest, this can be useful in developing programs and formulation of plans to achieve sustainability of beach forest resource utilization. Likewise, proper dissemination of the importance of the ecosystem, its benefits and transparent management strategies should be imposed in order to encourage the local communities to engage into organizations for sustainable management of the beach forest ecosystem.
\end{abstract}

Keywords: Resource management strategies, Sustainable management, Local knowledge,

Attitude and perception, Island community

Proceedings of the $22^{\text {nd }}$ International Forestry and Environment Symposium 2017 of the Department of Forestry and Environmental Science, University of Sri Jayewardenepura, Sri Lanka 